\title{
Investigation of the Differences between the Immunity of High- and Low-risk Anatomical Regions in Patients with Basal Cell Carcinoma: Is Neutrophil to Lymphocyte Ratio Associated with Regional Distribution of the Tumor?
}

\author{
(D) Erol KOZANOĞLU,' (D) Fethi Sarper METE, ${ }^{2}$ (D) Aret Çerçi ÖZKAN \\ 'Department of Plastic Reconstructive and Aesthetic Surgery, İstanbul University, Faculty of Medicine, İstanbul-Turkey \\ ${ }^{2}$ Department of Plastic Reconstructive and Aesthetic Surgery, Acıbadem Mehmet Ali Aydınlar University Halkalı Hospital, İstanbul-Turkey \\ ${ }^{3}$ Department of Plastic Reconstructive and Aesthetic Surgery, Private Practice, İstanbul-Turkey
}

\begin{abstract}
OBJECTIVE
Basal cell carcinoma (BCC) is the most commonly observed type of cancer. Neutrophil-to-lymphocyte ratio (NLR) is a measure of the immune status of patients, and the ratio increases as the tumor becomes aggressive. This study aims to compare the NLR of patients with tumors in high-risk $\mathrm{H}$ region and in the usual risk regions.
\end{abstract}

\section{METHODS}

Patients who were operated for BCC between January 2017 and May 2018 were included in this study. Patients were divided into two groups. Patients with tumors found in the high-risk $\mathrm{H}$ region, according to subclinical expansion, were classified as Group 1. Patients with tumors in other anatomical regions were classified as Group 2. Electronic file and photographs of each patient from the archives were examined and demographical data, as well as hemogram analyses, were recorded.

\section{RESULTS}

Forty-six cases were included in this study. Fourteen patients were female and 32 patients were male. The mean age of the patients was 64,6 years (33-87 years). The mean follow-up period was eight months (1-17 months). The NLR and thrombocyte to lymphocyte ratio of the patients did not show statistically significant differences between the groups $(\mathrm{p}>0.05)$.

\section{CONCLUSION}

The NLR does not distinguish between the H region and other regions in BCC concerning biological characteristics of the tumor.

Keywords: Basal cell carcinoma; H region; neutrophil to lymphocyte ratio; thrombocyte to lymphocyte ratio. Copyright $\odot$ 2020, Turkish Society for Radiation Oncology

\section{Introduction}

The risk of developing skin cancer during a lifetime is one in five individuals, and more than $97 \%$ of these are non-melanoma skin cancers.[1] Basal cell carcinoma, which is classified in the non-melanoma skin cancers, is the most common type of skin cancer.[2] Since the primary treatment of basal cell carcinoma 
is surgery, this group of patients represents a significant proportion of plastic and reconstructive surgery applications.

There are multiple factors in the etiology of basal cell carcinoma, including ultraviolet ray exposure, light skin color, Fitzpatrick 1 and 2 skin structure, radiotherapy, immune-deficiency, HIV infections, immunosuppressive treatments following organ transplants and various syndromes, such as Gorlin-Goltz syndrome.[3]

The nasolabial fold, nasal flank, eye contour, ear contour, and temporal region make up the $\mathrm{H}$ region of the face.[4] In this region, basal cell carcinoma spreads more broadly subclinically and is also called a high-risk region since recurrences are common. $[5,6]$ Embryological origin is often blamed for the aggressiveness of basal cell carcinoma in this region, and it is emphasized that these regions are areas of embryological folding.

Neutrophil to lymphocyte ratio (NLR) is a measure of the immune status of the patients and is used in the diagnosis and the follow-up of treatment in many diseases.[7] As the tumor becomes more aggressive, an increase in neutrophil count and neutrophil to lymphocyte ratio is expected. In cancer patients, the immune system, which is expected to protect the organism against tumor initiation and progression, has been shown to enhance the biological structure of cancer cells with the increased secretion of cytokines at the cellular level.[8] NLR, which is widely used in the oncological follow-up of colorectal, hepatobiliary and urogenital solid tumors [9], has also been used to demonstrate the effects of the immune system on melanoma and non-melanoma skin cancers. Basal cell carcinoma was found to show the lowest neutrophil to lymphocyte ratio among skin cancers [10], and the correlation of low neutrophil to lymphocyte ratios with less aggressive tumor biology was confirmed.

This study aims to compare the neutrophil to lymphocyte ratio of basal cell carcinoma cases in high-risk $\mathrm{H}$ region and basal cell carcinoma cases in usual risk areas to investigate whether the immune status of the patient plays a role in subclinical tumor expansion in high-risk anatomical regions.

\section{Materials and Methods}

The study proposal was presented at the May 2018 meeting of the Clinical Research Ethics Committee of our institution, and it was decided that ethics committee approval was not required due to the nature of the study.
No financial support from industry was received for this study, nor the authors have a financial relationship with any individuals, institutions and organizations that may be associated with this study.

This study was designed as a retrospective descriptive study, and the electronic patient files and photo archive of our clinic were used for this study. In this study, patients who were diagnosed with basal cell carcinoma using punch biopsy and whose surgical treatment was previously completed were evaluated concerning the anatomical distribution of the tumor and hemogram examination in the peripheral blood. It was aimed to determine whether the immune system has an effect on tumor behavior in different anatomical regions.

All patients who underwent surgery for basal cell carcinoma between January 2017 and May 2018 were included in this study. All patients included in this study had a preoperative histopathological diagnosis by punch biopsy. The patients were divided into two groups according to the anatomical location of their tumors. Patients with tumors located in the $\mathrm{H}$ region in which subclinical expansion risk and recurrence rate are high were evaluated as Group 1. The patients whose tumors were located in the other anatomical regions of the face and body were evaluated as Group 2. Hemogram analyses of all patients were performed seven days before the surgery, and it was recorded that none of the patients represented clinical infection. In addition, no history of the immunosuppressive disease or drug use was detected in the records of patients included in this study.

Tumor resection was performed by the same surgeon with five-millimeter intact macroscopic margins, and all patients underwent reconstruction options, such as primary repair, grafting, and local flap repair. All pathology specimens were evaluated by the same physicians in the dermatopathology laboratory of the pathology clinic of our institution. Follow-up of the patients was performed on the postoperative first, fourth, fourteenth days and third months and was recorded in the electronic patient files.

Electronic files and archived photographs of each patient were examined, and the following data were recorded: age, sex, anatomical region of the tumor, histological subtype of tumor, applied reconstruction option, hemogram values from one week before operation (leukocyte count, lymphocyte count, monocyte count, neutrophil count, thrombocyte count, neutrophil to lymphocyte ratio, thrombocyte to lymphocyte ratio) and presence of relapse. 


\section{Results}

Forty-six patients who underwent surgery for basal cell carcinoma in our clinic between January 2017 and May 2018 were included in this study. Fourteen of the patients were female $(30.4 \%)$, and 32 patients $(69.6 \%)$ were male. The mean age of the patients at the last follow-up visit in May 2018 was 64.6 years (33-87 years). The mean follow-up period was eight months (1-17 months). It was observed that 30 subjects $(65.2 \%)$ belonged in Group 1 with high-risk $\mathrm{H}$ region tumors, whereas 16 subjects (34.8\%) belonged in Group 2 with tumors in other anatomical regions (Table 1, Fig. 1).

Histological subtypes of the patients included in this study were as follows: $2.2 \%(\mathrm{n}=1)$ adenocystic, $4.3 \%(\mathrm{n}=2)$ metatypic, $2.2 \%(\mathrm{n}=1)$ metatypic and morpheic, 2.2\% $(\mathrm{n}=1)$ morpheic, $47.8 \%(\mathrm{n}=22)$ nodular, $19.6 \%(\mathrm{n}=9)$ ulceronodular and $21.7 \%(\mathrm{n}=10)$ superficially expanding (Fig. 2). Grafting in $47.8 \%(\mathrm{n}=22)$, Limberg flap in $4.3 \%(n=2)$, primary repair in $45,7 \%$

\begin{tabular}{|c|c|}
\hline \multicolumn{2}{|l|}{ Age (years) } \\
\hline Min-Max (Median & $33-87$ (64) \\
\hline Mean $\pm S D$ & $64.63 \pm 13.68$ \\
\hline \multicolumn{2}{|l|}{ Sex } \\
\hline Female & $14(30.4)$ \\
\hline Male & $32(69.6)$ \\
\hline \multicolumn{2}{|l|}{ Anatomic region } \\
\hline Group 1 & $30(65.2)$ \\
\hline Group 2 & $16(34.8)$ \\
\hline
\end{tabular}

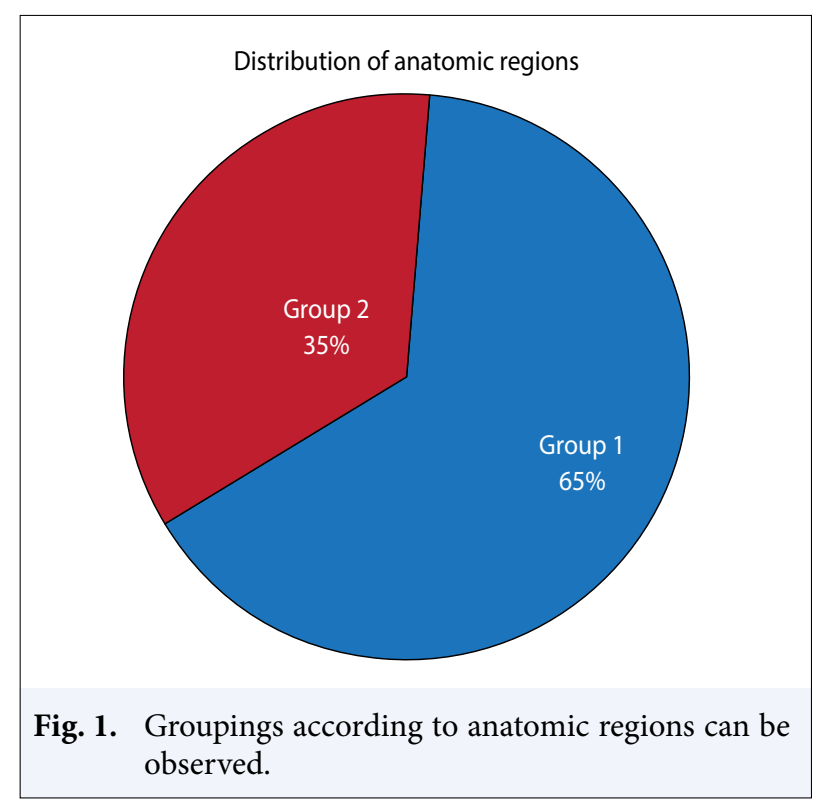

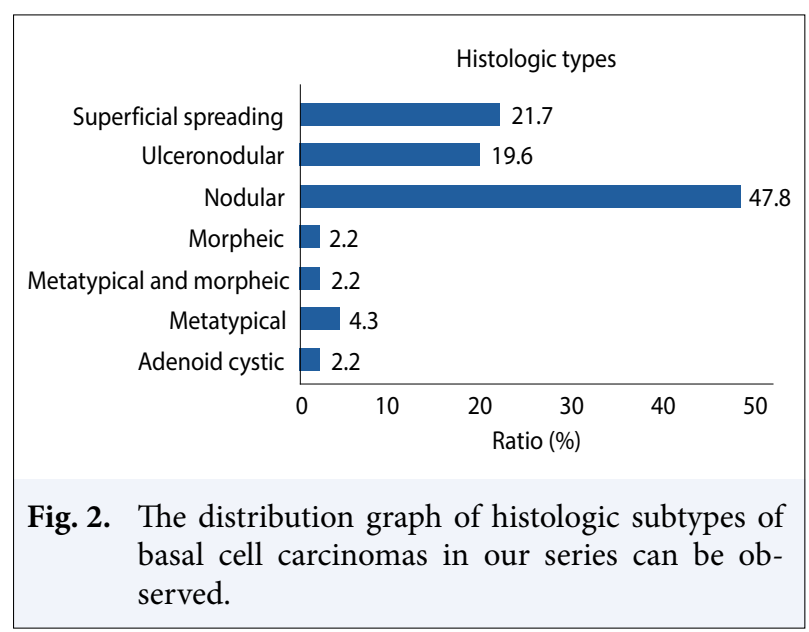

$(\mathrm{n}=21)$ and shark flap in $2.2 \%(\mathrm{n}=1)$ of the cases were preferred for reconstruction (Fig. 3, Table 2).

The numerical values in the hemogram analyses of the cases are absolute values in cubic millimeters of blood. Leukocyte measurements of the patients ranged from 4700 to 15130 , with an average of $8059.78 \pm 2444.05$. Lymphocyte measurements ranged from 810 to 7130 , with an average of $2419.35 \pm 1065.30$. Monocyte measurements ranged from 350 to 2580 , with an average of $655.43 \pm 348,57$. Neutrophil measurements ranged from 2100 to 10600 , with an average of $4718.04 \pm 1694.58$. Thrombocyte measurements ranged from 23000 to

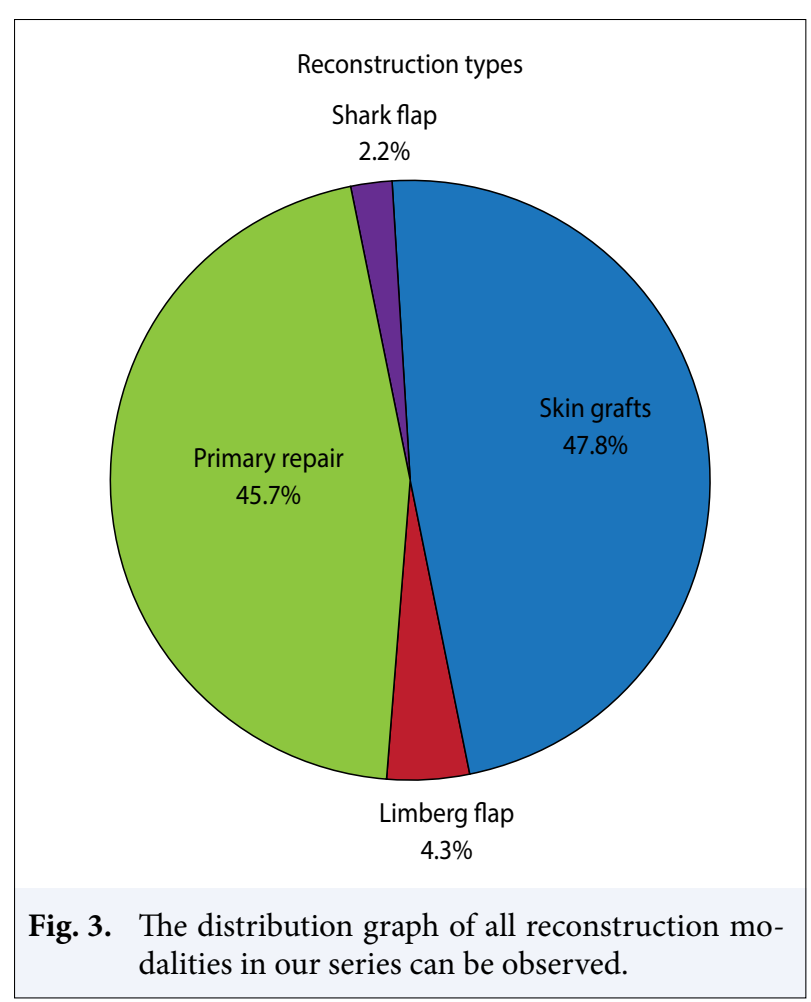


Table 2 Distribution of the complementary features

$\begin{array}{lc}\text { Histological type } & \\ \text { Adenoid cystic } & 1(2.2) \\ \text { Metatypic } & 2(4.3) \\ \text { Metatypic \& morpheic } & 1(2.2) \\ \text { Morpheic } & 1(2.2) \\ \text { Nodular } & 22(47.8) \\ \text { Ulceronodular } & 9(19.6) \\ \text { Superficially invasive } & 10(21.7) \\ \text { Reconstruction type } & \\ \text { Grafting } & 22(47.8) \\ \text { Limberg flap } & 2(4.3) \\ \text { Primary } & 21(45.7) \\ \text { Shark flap } & 1(2.2)\end{array}$

447000 , with an average of $253739.13 \pm 77292.64$. Neutrophil to lymphocyte ratios ranged from 0.7 to 6.73 , with an average of $2.21 \pm 1.11$, while thrombocyte to lymphocyte ratios ranged from 12.78 to 298.77 , with an average of $120.51 \pm 58.75$ (Table 3 ).

The difference between the mean ages of the groups was statistically not significant ( $p>0.05)$. Similarly, there was no statistically significant difference between the gender distribution of the groups ( $\mathrm{p}>0.05)$.
Distribution of reconstruction types according to groups

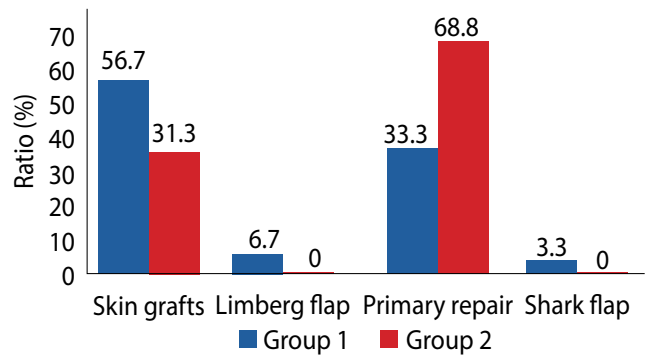

Fig. 4. The comparative graph of reconstruction modalities according to groups can be observed.

Leukocyte, lymphocyte, monocyte, neutrophil, thrombocyte, neutrophil to lymphocyte ratio and thrombocyte to lymphocyte ratio measurements of the patients did not show statistically significant differences between the two groups ( $p>0.05$ ) (Table 3 ).

There was no statistically significant difference between the distribution of histological subtypes of the patients between the two groups ( $\mathrm{p}>0.05)$ (Table 4).

There was a statistically significant difference between the groups according to the distribution of re-

Table 3 Evaluation of laboratory findings according to groups

\begin{tabular}{|c|c|c|c|}
\hline & \multicolumn{2}{|c|}{ Groups } & \multirow{2}{*}{$\begin{array}{c}\text { Test value } \\
\text { p }\end{array}$} \\
\hline & Group $1(n=30)$ & Group $2(n=16)$ & \\
\hline \multicolumn{4}{|l|}{ Leukocyte } \\
\hline Min-Max (Median) & $5420-15130(7295)$ & $4700-11770(7530)$ & $Z=-0.358$ \\
\hline Mean \pm SD & $8183.33 \pm 2734.76$ & $7828.13 \pm 1836.63$ & ${ }^{c} 0.721$ \\
\hline \multicolumn{4}{|l|}{ Lymphocyte } \\
\hline Min-Max (Median) & $810-7130(2150)$ & $1250-3640(2560)$ & $\mathrm{t}=0.233$ \\
\hline Mean \pm SD & $2392.33 \pm 1208.29$ & $2470 \pm 760.12$ & ${ }^{\mathrm{a}} 0.817$ \\
\hline \multicolumn{4}{|l|}{ Monocyte } \\
\hline Min-Max (Median) & $350-2580(590)$ & $390-1050(575)$ & $Z=-0.058$ \\
\hline Mean \pm SD & $680.33 \pm 409.92$ & $608.75 \pm 189.91$ & ${ }^{c} 0.954$ \\
\hline \multicolumn{4}{|l|}{ Neutrophil } \\
\hline Min-Max (Median) & $2100-10600(4470)$ & $2360-6940(4245)$ & $t=0.677$ \\
\hline Mean \pm SD & $4842.33 \pm 1874.2$ & $4485 \pm 1317.17$ & a 0.502 \\
\hline \multicolumn{4}{|l|}{ Thrombocyte } \\
\hline Min-Max (Median) & $23000-438000$ & $143000-447000$ & $t=0.003$ \\
\hline Mean \pm SD & $(249500)$ & $(237000)$ & a 0.997 \\
\hline \multicolumn{4}{|c|}{ Neutrophil/lymphocyte } \\
\hline Min-Max (Median) & $0.7-6.73(2.16)$ & $1.17-4.66(1.72)$ & $t=1.029$ \\
\hline Mean \pm SD & $2.33 \pm 1.2$ & $1.98 \pm 0.92$ & ${ }^{\mathrm{a}} 0.309$ \\
\hline \multicolumn{4}{|c|}{ Thrombocyte/lymphocyte } \\
\hline Min-Max (Median) & 12.78-298.77 (106.99) & $58.79-261.6(95.7)$ & $Z=-0.946$ \\
\hline Mean \pm SD & $125.46 \pm 63.48$ & $111.24 \pm 49.24$ & ${ }^{c} 0.344$ \\
\hline
\end{tabular}

a: Student-t test; ${ }^{c}$ : MannWhitney U test 
Table 4 Histological types and reconstruction models according groups

\begin{tabular}{|c|c|c|c|}
\hline & \multicolumn{2}{|c|}{ Groups } & \multirow{2}{*}{$\begin{array}{c}\text { Test value } \\
\text { p }\end{array}$} \\
\hline & $\begin{array}{c}\text { Group } 1(n=30) \\
n(\%)\end{array}$ & $\begin{array}{c}\text { Group } 2(n=16) \\
n(\%)\end{array}$ & \\
\hline \multicolumn{4}{|l|}{ Histological type } \\
\hline Adenoid cystic & $0(0.0)$ & $1(6.3)$ & $\chi^{2}: 4.958$ \\
\hline Metatypic & $1(3.3)$ & $1(6.3)$ & ${ }^{d} 0.609$ \\
\hline Metatypic \& morpheic & $1(3.3)$ & $0(0.0)$ & \\
\hline Morpheic & $1(3.3)$ & $0(0.0)$ & \\
\hline Nodular & $15(50.0)$ & $7(43.8)$ & \\
\hline Ulceronodular & $7(23.3)$ & $2(12.5)$ & \\
\hline Superficial spreading & $5(16.7)$ & $5(31.3)$ & \\
\hline \multicolumn{4}{|l|}{ Reconstruction type } \\
\hline Grafting & $17(56.7)$ & $5(31.3)$ & $\chi^{2}: 2.701 ;{ }^{e} 0.100$ \\
\hline Limberg flap & $2(6.7)$ & $0(0.0)$ & $\chi^{2}: 1.155 ;{ }^{b} 0.531$ \\
\hline Primary & $10(33.3)$ & $11(68.8)$ & $\chi^{2}: 4.865 ;{ }^{\text {e }} 0.027^{*}$ \\
\hline Shark flap & $1(3.3)$ & $0(0.0)$ & $\chi^{2}: 0.564 ;{ }^{b} 1.000$ \\
\hline
\end{tabular}

b: Fisher's exact test; ${ }^{d}$ : Fisher Freeman Halton test; ${ }^{\text {: }}$ Pearson Chi square test

pair choices. Grafting, Limberg flap, and shark flap repairs did not differ significantly between groups ( $>0.05$ ), while the primary repair was performed at a significantly lower level in patients at high-risk group $(p<0.05)$. It was found that grafting was applied to the high-risk group at a higher rate, but the difference was not statistically significant (Fig. 4, Table 4).

For statistical analyses, the NCSS 2007 (Number Cruncher Statistical System) (Kaysville, Utah, USA) program was used. For the evaluation of the study data, Student's t-test was used for the comparison of the two groups for variables with normal distribution, as well as the descriptive statistical parameters (such as mean, standard deviation, median, frequency, ratio, minimum, maximum). Mann-Whitney $U$ test was used for the comparison of two groups for variables that do not show normal distribution. Pearson chi-square test, Fisher's exact test, and the Fisher Freeman Halton test were used to compare qualitative data. Statistical significance was evaluated as p-values lower than 0.05 .

\section{Discussion}

Basal cell carcinoma, considered within the non-melanoma skin cancers classification, is the most common type of cancer.[2] Since the incidence of skin cancers is not quantified in any health registry system around the world, there are various estimates of the frequency of basal cell carcinoma.[11] According to the World Health Organization, two to three million people worldwide are diagnosed with non-melanoma skin cancers annually, and one in every three individuals diagnosed with cancer has skin cancer.[12] Considering the frequency of basal cell carcinoma, further studies are needed to improve the diagnosis, treatment, and follow-up of this clinical picture. In this study, we aimed to explain the differences between the recurrence tendencies of basal cell carcinomas in different anatomical regions from the immune system point of view by using basic hematological data obtained at the diagnosis stage.

The study published by Muzic et al. in 2017 contains the most recent data concerning epidemiology and demographic evaluation of non-melanoma skin cancers.[11] The mean age of 3325 patients with basal cell carcinoma was 63.4 years, while $50.2 \%$ of the patients were male in their study. The mean age of 46 patients included in our study was 64.6 years, which is consistent with the literature, whereas $69.6 \%$ of the patients were male, which is different from the previous study. However, our study could not detect a cause that might cause a difference in the gender distribution of the patients.

Many factors have been identified that might cause basal cell carcinoma. Ultraviolet radiation exposure from the sun or artificial sources, Fitzpatrick 1 and 2 skin structure, previous radiotherapy, various genetic syndromes, human immunodeficiency virus infection and immunosuppressive treatments for various purposes are the main agents causative for basal cell carcinoma.[2] 
Nasolabial folds, nose wings, both eye and ear contours are called the $\mathrm{H}$ region of the face.[13] Choi et al. found $\mathrm{H}$ region involvement in 45 (59\%) of 76 basal cell carcinoma patients 13 and $65.2 \% \mathrm{H}$ region involvement detected in our study was consistent with the current literature.

The relationship between anatomic regions and subtypes of basal cell carcinoma was evaluated in a study conducted in 2000 by Kim et al., and they suggested that nodular subtype was more frequent in both $\mathrm{H}$ region and other regions.[14] Besides, nodular subtype was found in almost all cases in the embryological fold areas within the $\mathrm{H}$ region.[14] In our study, the most common subtype was nodular in all regions and no difference was found between the $\mathrm{H}$ region and other regions concerning histological subtypes. Accordingly, anatomical distribution does not affect tumor histology.

The entire $\mathrm{H}$ region, particularly the inverse triangle located between both external canthus and the upper lip philtrum, are areas where basal cell carcinoma is more prone to regional expansion and relapse.[14,15] The $\mathrm{H}$ region contains anatomical, embryological folds and covers the most protruding structures of the body, such as the nose, which increases ultraviolet radiation exposure.[13] Although these factors are prominent, no certain factor has been revealed for the basal cell carcinoma behavior in the $\mathrm{H}$ region. This study was carried out with the hypothesis that subclinical immunodeficiency is a factor in the basal cell carcinoma biology in the $\mathrm{H}$ region.

The role of systemic inflammation and immune deficiency in cancer initiation and progression has been previously proven.[16] Neutrophil to lymphocyte ratio in peripheral blood is a measure of systemic inflammation and the state of an individual's immune status. The increase in neutrophils that indicate acute inflammation and the decrease in lymphocytes that are the main cells governing the immune system cause the neutrophil to lymphocyte ratio to increase and this is an indication of poor prognosis in various cancers. [17] Few publications in the literature use neutrophil to lymphocyte ratio for the evaluation of skin cancers. In the study conducted by Baykan et al. (2015), malignant melanoma, squamous epithelial cell carcinoma, and basal cell carcinoma were compared concerning neutrophil to lymphocyte ratios, and it was shown that basal cell carcinoma has the lowest neutrophil to lymphocyte ratio among all skin cancers. [10] Considering that basal cell carcinoma is the most benign skin cancer concerning the tendency to spread and relapse
[2], it can be suggested that neutrophil to lymphocyte ratios can be used in skin cancers.

In our study, hemogram analyses obtained at a standard preoperative time from patients without acute inflammation were used to evaluate neutrophil to lymphocyte ratios. We could not detect a statistically significant difference between neutrophil to lymphocyte ratios in the $\mathrm{H}$ region and other anatomical regions. This suggests that immune changes are not a factor in invasive and recurrent tumor biology in the $\mathrm{H}$ region. In this study, no additional factor could be identified concerning tumor behavior in the $\mathrm{H}$ region other than embryological folding and overexposure to ultraviolet rays.

Choi et al. more frequently applied primary repair after the excision of basal cell carcinomas in the $\mathrm{H}$ region.[13] The different reconstruction preferences between the anatomical regions in this study is an important and different finding from the literature. In the $\mathrm{H}$ region, the primary repair was applied significantly less frequently, while grafting or flap repair options were more preferred. Due to the anatomical features of the $\mathrm{H}$ region, primary repair may not yield satisfactory results in the aesthetic sense. In the multilayered loss of anatomical structures, such as nose wings, ear, and eyelids, composite tissue transplants involving multiple tissues, are required. In addition, although this study did not evaluate tumor diameters, it was observed that the mean tumor diameter in the $\mathrm{H}$ region was greater than the other regions. This is one of the main reasons for withdrawal from primary repair. Although statistically not significant, graft repair in the $\mathrm{H}$ region is more preferred over the flap repair and compared to the other regions. This is possibly due to the doctrine taught to students during plastic and reconstructive surgery education that basal cell carcinoma has a greater tendency to spread and relapse in the $\mathrm{H}$ region. Grafting is more preferred for the follow-up of recurrence of tumors in the $\mathrm{H}$ region.

\section{Conclusion}

The $\mathrm{H}$ region, which has a higher tendency to subclinical spreading and recurrence of basal cell carcinoma, is considered a high-risk region. Neutrophil to lymphocyte ratio, which is a novel measurement used in the follow-up and prognosis of skin tumors, does not make a distinction between the $\mathrm{H}$ region of basal cell carcinoma and other anatomical regions concerning the biological characteristics of the tumor. To our knowledge, this is the first study in the literature exam- 
ining the anatomical region and basal cell carcinoma immunology. Further studies are needed to determine whether the immune system has an additional effect on the biological behavior of basal cell carcinoma in different anatomical regions.

Peer-review: Externally peer-reviewed.

Conflict of Interest: No conflicts of interest exist between the authors. The authors have no disclosures.

Ethics Committee Approval: The study proposal was presented at the May 2018 meeting of the Clinical Research Ethics Committee of our institution, and it was decided that ethics committee approval was not required due to the nature of the study.

Financial Support: The authors received no financial supports. The authors do not have any disclosures.

Authorship contributions: Concept - E.K.; Design - E.K.; Supervision - A.Ç.Ö., F.S.M.; Funding - None; Materials E.K., F.S.M.; Data collection and/or processing - E.K., F.S.M.; Data analysis and/or interpretation - E.K., A.Ç.Ö.; Literature search - E.K., A.Ç.Ö.; Writing - E.K.; Critical review - E.K., F.S.M., A.Ç.Ö.

\section{References}

1. Rigel DS, Friedman RJ, Kopf AW. Lifetime risk fordevelopment of skin cancer in the U.S. population: currentestimate is now 1 in 5. J Am Acad Dermatol 1996;35(6):1012-3.

2. Marzuka AG, Book SE. Basalcellcarcinoma: pathogenesis, epidemiology, clinicalfeatures, diagnosis, histopathology, andmanagement. Yale J Biol Med 2015;88(2):167-79.

3. Correia de Sá TR, Silva R, Lopes JM. Basalcellcarcinoma of the skin (part 1): Epidemiologypathologyandgeneticsyndromes. Future Oncol 2015;11(22):3011-21.

4. Baxter JM, Patel AN, Varma S. Facial basal cell carcinoma. BMJ 2012;345:e5342.

5. Batra RS, Kelley LC. Predictors of extensive subclinical spread in nonmelanoma skin cancer treated with Mohs micrographic surgery. Arch Dermatol 2002;138(8):1043-51.
6. Margo CE, Waltz K. Basal cell carcinoma of the eyelid and periocular skin. Surv Ophthalmol 1993;38(2):16992.

7. Forget P, Khalifa C, Defour JP, Latinne D, Van Pel MC, De Kock M. What is the normal value of the neutrophil-to-lymphocyte ratio? BMC Res Notes 2017;10(1):12.

8. Mantovani A, Allavena P, Sica A, Balkwill F. Cancerrelated inflammation. Nature. 2008;454(7203):436-44.

9. Templeton AJ, McNamara MG, Šeruga B, Vera-Badillo FE, Aneja P, Ocaña A, et al. Prognostic role of neutrophil-to-lymphocyte ratio in solid tumors: a systematic review and meta-analysis. J Natl Cancer Inst 2014 29;106(6):dju124.

10. Baykan H, Cihan YB, Ozyurt K. Roles of White blood cells and subtypes as inflammatorymarkers in skin cancer. Asian Pac J Cancer Prev 2015;16(6):2303-6.

11. Muzic JG, Schmitt AR, Wright AC, Alniemi DT, Zubair AS, Olazagasti Lourido JM, et al. Incidence and Trends of Basal Cell Carcinoma and Cutaneous Squamous Cell Carcinoma: A Population-Based Study in Olmsted County, Minnesota, 2000 to 2010. Mayo Clin Proc 2017;92(6):890-8.

12. Skin cancers. World HealthOrganizationWebsite. Available at: http://www.who.int/uv/faq/skincancer/ en/index1.html. Accessed Feb 3, 2020.

13. Choi JH, Kim YJ, Kim H, Nam SH, Choi YW. Distribution of Basal cell carcinoma and squamous cell carcinoma by facial esthetic unit. Arch Plast Surg 2013;40(4):387-91.

14. Kim JW, Oh CH, Kim IH. Distribution of histologic subtypes of basal cell carcinoma by facial aesthetic unit and subunit. Korean J Dermatol 2000;38(1):31-7.

15. Mora RG, Robins P. Basal-cell carcinomas in the center of the face: special diagnostic, prognostic, and therapeutic considerations. J Dermatol Surg Oncol 1978;4(4):315-21.

16. Grivennikov SI, Greten FR, Karin M. Immunity, inflammation, and cancer. Cell 2010;140(6):883-99.

17. Guthrie GJ, Charles KA, Roxburgh CS, Horgan PG, McMillan DC, Clarke SJ. The systemic inflammation-based neutrophil-lymphocyte ratio: experience in patients with cancer. Crit Rev Oncol Hematol 2013;88(1):218-30. 